\title{
Endovascular treatment for traumatic thoracic aortic pseudoaneurysm: a case report
}

\author{
Po-Sung Li ${ }^{1,4}$, Chung-Lin Tsai ${ }^{1,2,4}$, Tzu-Chieh Lin ${ }^{1,4}$, Siu-Wan Hung ${ }^{3,5,8}$ and Sung-Yuan Hu, ${ }^{1,4,6,7^{*}}$
}

\begin{abstract}
Cases of an endovascular treatment for traumatic aortic injury are extremely rare. A prompt diagnosis of traumatic thoracic aortic pseudoaneurysm through a 3-dimensional computed tomographic angiography of aorta and emergency repair are mandatory to rescue the life-threatening condition. An endovascular treatment is a trend for traumatic aortic injury because of lower invasivity, morbidity and mortality. We reported a rare case of traumatic aortic injury with thoracic aortic pseudoaneurysm definitively diagnosed by the reconstructional computed tomographic angiography of aorta and successfully treated with endovascular stent-graft.
\end{abstract}

Keywords: Computed tomographic angiography (CTA), Endovascular stent-graft, Thoracic aortic pseudoaneurysm (TAPA), Traumatic aortic injury (TAI)

\section{Background}

Traumatic aortic injury has been associated with a lethal surgical lesion and a high mortality in blunt chest trauma. The risk of aortic rupture in traumatic aortic injury has been reported approximately $5 \%$ in the acute phase [1]. Thoracic aortic pseudoaneurysm is a rare and life-threatening complication of traumatic aortic injury with an incidence of $2 \%-5 \%$ [2]. The most commonly involved site is isthmus. $93 \%-98 \%$ of patients with traumatic aortic injury have been a definitive diagnosis by computed tomographic scan and thoracic aortic pseudoaneurysm in computed tomographic scan is a direct sign of traumatic aortic injury [1-3]. In hemodynamic unstable patients of traumatic aortic injury, an endovascular treatment with stent-graft offers a suitable alternative to open surgical intervention [1,4-8].

\section{Case presentation}

A 28-year-old healthy unmarried woman committed suicide with a high-rise fall of 20 meters and presented hypovolemic shock caused by blunt thoracic, abdominal injury and left femoral shaft fracture to our emergency department. Upon admission, vital signs were respiratory rate of $22 / \mathrm{min}$, blood pressure of $88 / 40 \mathrm{mmHg}$, pulse

\footnotetext{
*Correspondence: song9168@pie.com.tw

'Department of Emergency Medicine, Taichung Veterans General Hospital, Taichung, Taiwan

${ }^{4}$ School of Medicine, Chung Shan Medical University, Taichung, Taiwan

Full list of author information is available at the end of the article
}

rate of $106 / \mathrm{min}$, and body temperature of $33^{\circ} \mathrm{C}$. Physical examination showed a $5 \mathrm{~cm}$-laceration wound over submandible, a Glasgow Coma Scale of E1V2M1, rapid regular heart beats, absent breathing sound of left lung filed, tenderness over upper abdominal region and deformity with tenderness of left thigh. Standard advanced trauma life support with an endotracheal intubation for protection of airway, fluid resuscitation with normal saline and blood transfusion for unstable hemodynamic status and essential survey of images was conducted. Laboratory investigations were white blood cell counts of $9,300 / \mathrm{mm}^{3}$, hemoglobin of $11.3 \mathrm{~g} / \mathrm{dl}$, platelet counts of $287 \times 10^{3} / \mathrm{mm}^{3}$, blood urea nitrogen of $15 \mathrm{mg} / \mathrm{dl}$, creatinine of $1.0 \mathrm{mg} / \mathrm{dl}$, sodium $137 \mathrm{mEq} / \mathrm{l}$, potassium $3.4 \mathrm{mEq} / \mathrm{l}$, calcium $7.4 \mathrm{~g} / \mathrm{dl}$, albumin $3.3 \mathrm{of} \mathrm{g} / \mathrm{dl}$, total protein of $6.0 \mathrm{~g} / \mathrm{dl}$, glutamic-oxalacetic transaminase of $711 \mathrm{U} / \mathrm{l}$, glutamic-pyruvic transaminase of $302 \mathrm{U} / \mathrm{l}$, lactic dehydrogenase of $1002 \mathrm{U} / \mathrm{l}$, creatine kinase of $485 \mathrm{U} / \mathrm{l}$, and troponin-I of $<0.034 \mathrm{ng} / \mathrm{ml}$. Arterial blood gas analysis was a $\mathrm{pH}$ of $7.190, \mathrm{P}_{\mathrm{a}} \mathrm{O}_{2}$ of $85.5 \mathrm{mmHg}, \mathrm{P}_{\mathrm{a}} \mathrm{CO}_{2}$ of $39.2 \mathrm{mmHg}$, and $\mathrm{HCO}^{-}$of $14.6 \mathrm{mmol} / \mathrm{l}$. Chest plain film demonstrated a fracture of left first rib, abnormal contour of aortic arch with hemothorax and patchy infiltration at right lower lung suggestive of aortic injury and lung contusion (Additional file 1: Figure S1). Plain film of left femur showed a fracture of femoral shaft (Additional file 1: Figure S2). The reconstructional images through contrastenhanced computed tomographic angiography (CTA)
C Biomed Central

(c) 2013 Li et al.; licensee BioMed Central Ltd. This is an Open Access article distributed under the terms of the Creative Commons Attribution License (http://creativecommons.org/licenses/by/2.0), which permits unrestricted use, distribution, and reproduction in any medium, provided the original work is properly cited. 


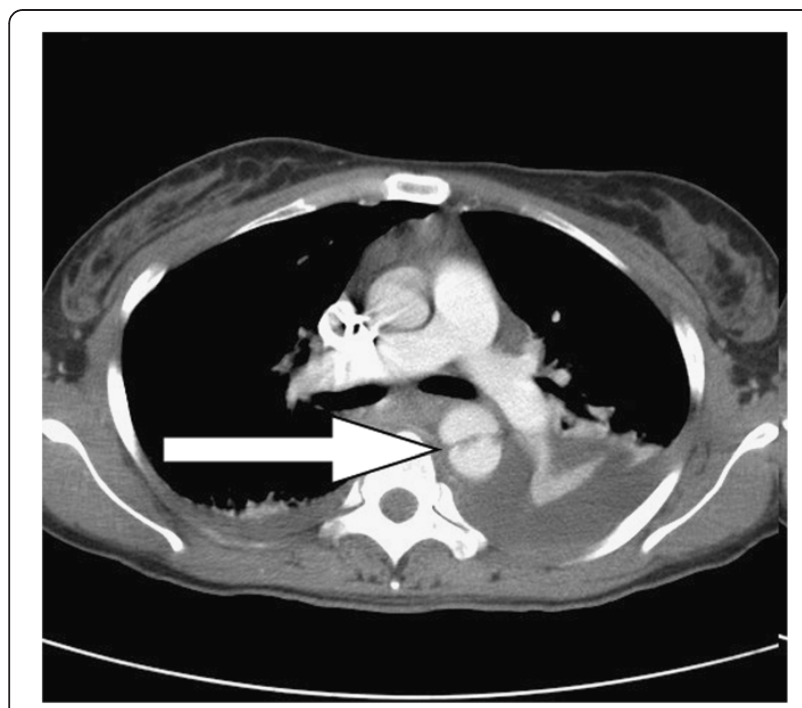

Figure 1 The axial view of computed tomographic angiography (CTA) revealed a dumbbell-shaped aorta (arrow) with hemothorax and hemomediastinum consistent with a ruptured thoracic aortic pseudoaneurysm.

of aorta demonstrated a thoracic aortic pseudoaneurysm (TAPA) of $16 \mathrm{~mm} \times 30.6 \mathrm{~mm}$ (Figures 1, 2 and 3) with hemothorax, hemomediastinum and liver laceration of left lobe with hemoperitoneum (Additional file 1: Figure S3). Six hours later, an endovascular treatment with stent-graft (Figure 4) was performed successfully. Open reduction with internal fixation for fracture of left femoral shaft was

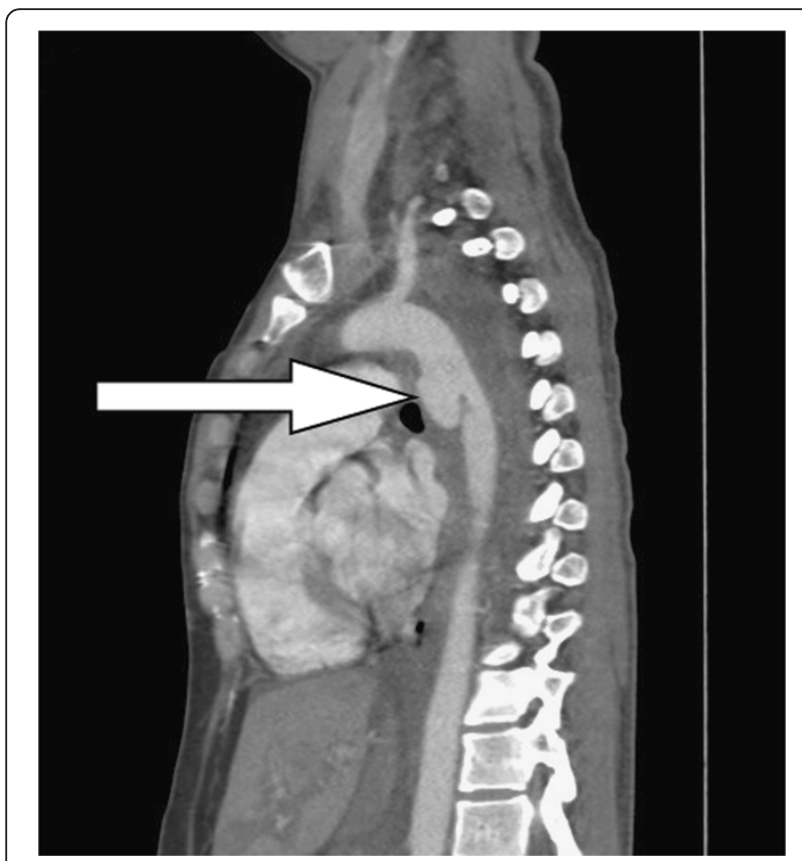

Figure 2 The coronal view of CTA depicted a thoracic aortic pseudoaneurysm (arrow) below the aortic arch, hemothorax and hemomediastinum.

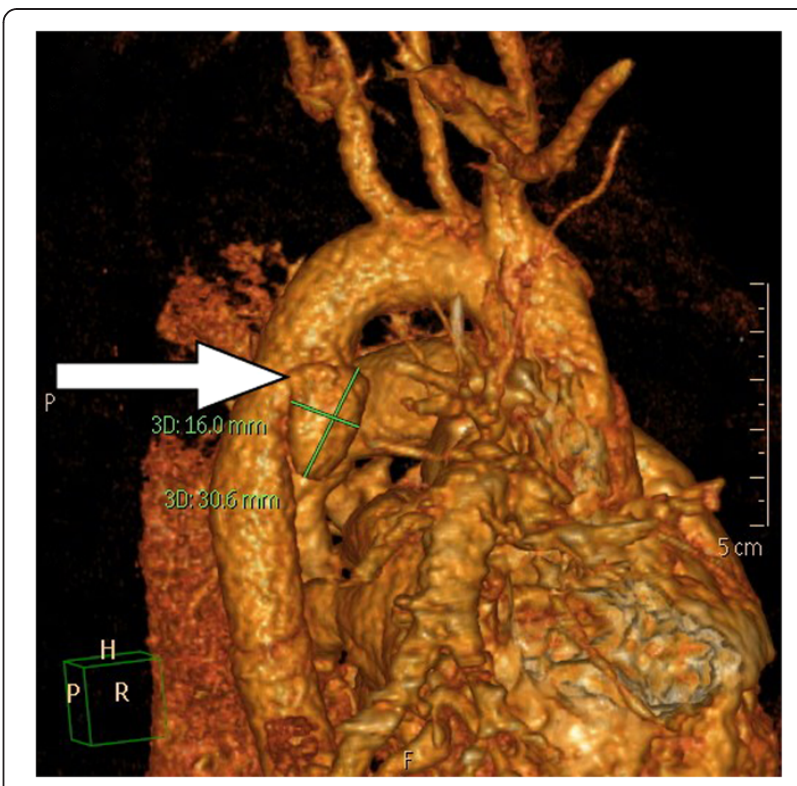

Figure 3 The reconstructional image of CTA demonstrated a thoracic aortic pseudoaneurysm of $16 \mathrm{~mm} \times 30.6 \mathrm{~mm}$ (arrow) in size.

performed 6 days later. She was ultimately discharged on the 18th postoperative day after an uneventful admission.

\section{Discussion}

Chest trauma is classified as blunt or penetrating and the former is the most cause of thoracic injuries with an

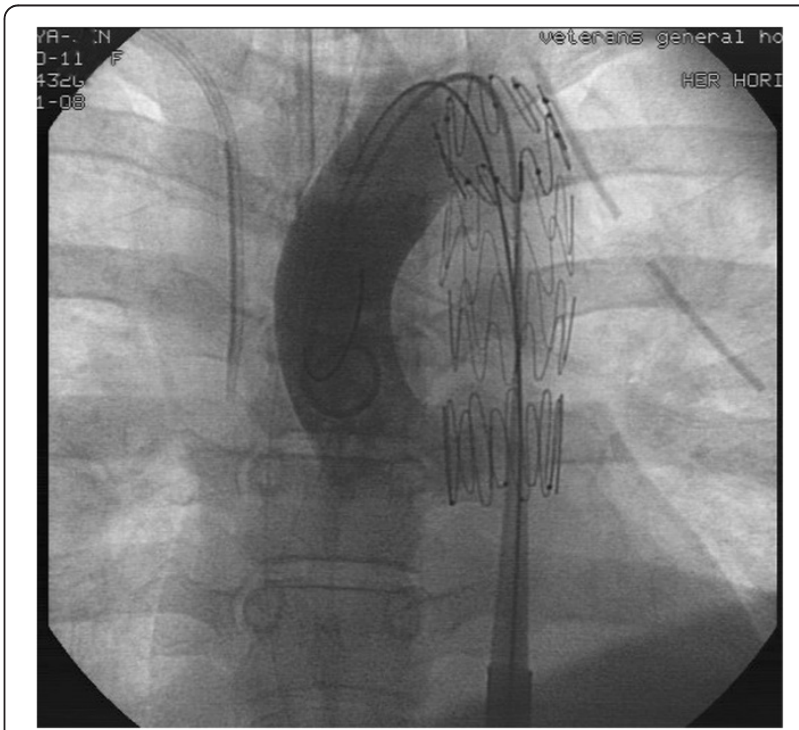

Figure 4 An emergency aortography and an endovascular repair with a fenestrated stent-graft $\left(\mathrm{COOK}^{\circledR}\right.$, Zenith ${ }^{\circledR} \mathrm{TX2}{ }^{\circledR}$ TAA Endovascular Graft, Proximal Extensions, Order number: TBE-26-80) were conducted successfully for the thoracic aortic pseudoaneurysm. 
incidence of $90 \%$. The prevalence of thoracic injuries caused by falls from heights is $10-20 \%$. Traumatic aortic rupture is a very rare condition with an average of 2.2 cases per center per year reported in North America. Thoracic great vessel related to blunt trauma is relatively rare with an incidence of less than 5\% [5-8].

The mechanism is torsion and shearing forces against the aorta at levels of relative immobility, mainly the ligamentum arteriosum with an incidence of $90-95 \%$. The isthmus, a part of relatively mobile thoracic aorta joining the fixed arch and the insertion of the ligamentum arteriosus, becomes the most commonly injured site in deceleration accident, with an involved incidence of $80 \%$ and $90-95 \%$ in the pathological and clinical series, respectively [1-8].

The traumatic aortic injury (TAI), a lesion extending from the intima to the adventitia, usually occurs in deceleration accidents, such as motor vehicle collisions, falls from height or crush injuries, with an immediately high mortality rate of $80-90 \%$ during the first phase, so the victims should be taken to hospital as quickly as possible. Survival patients in the initial phase of TAI have a higher successful outcome under endovascular repair comparative of conventional open surgical repair [1-8]. The predictors of TAI include age older than 50 years, being unrestrained, systolic blood pressure of less than $90 \mathrm{mmHg}$, thoracic injury, abdominopelvic injury with fractures of the lumbar spine and pelvis, long bone fractures, and major head injury [7].

Widening of mediastinum greater than $8 \mathrm{~cm}$ and/or $25 \%$ of the width of the thorax, loss of aortico-pulmonary window, tracheal deviation to the right, nasogastric shifting to right, left apical cap, depression of the left main stem bronchus, left-sided hemothorax, or scapular, sternal, thoracic spine or multiple rib fractures on plain radiography is suggestive of aortic rupture $[5,7,9]$. Fractures of the first and second ribs are clearly markers of severe blunt force trauma $[7,9]$.

Multidetector CTA is the diagnostic modality for the initial evaluation and accurate diagnosis of TAI, with a sensitivity of $98 \%$ and a specificity of $100 \%[6,7]$. CTA can offer a non-invasive assessment of the anatomical characteristics of TAI with rapid deceleration force or clinical suspicion. A prompt diagnosis of traumatic TAPA through a 3-dimensional CTA of aorta and emergency repair with stent graft are mandatory to rescue the lifethreatening condition. An endovascular repair is a trend with greater and greater acceptance for TAI because of lower invasivity, avoiding thoracotomy and use of heparin, lower morbidity and mortality compared with conventional open surgical repair [1-10].

Pseudoaneurysm formation, intraluminal filling defect, and intimal irregularity are common findings in vessel wall injury [7]. Direct signs of TAI include active contrast medium extravasation, an intimal flap, TAPA, an increase in size of the periaortic hematoma, aortic contour/ diameter variation, contained rupture, intraluminal mural thrombus, abnormal aortic contour, recurrent hemothorax and abrupt change in aortic caliber (pseudocoarctation) $[1-3,6,7]$. Indirect CT signs are indistinctness of mediastinal flat planes, periaortic haematoma and mediastinal haematoma $[2,3,6]$.

Short-term complications of endovascular repair for TAI include paraplegia, stroke, puncture-site complications, device collapse, endoleak and recurrent laryngeal nerve damage. However, very little data are available concerning long-term outcomes and complications [5,7]. We highlight that CTA and emergency endovascular repair of stent-graft for TAI with TAPA in polytrauma patients are recommended.

\section{Conclusion}

Prompt diagnosis and management of highly suspicious patients with traumatic thoracic aortic pseudoaneurysm caused by blunt chest injury is associated with the good prognosis. We provide the successful experience of a less invasive intervention with an endovascular stent-graft for traumatic thoracic aortic pseudoaneurysm through the mechanism of rapid deceleration.

\section{Consent}

Written informed consent was obtained from the patient for publication of this case report and accompanying images. A copy of the written consent is available for review by the Editor-in-Chief of this journal.

\section{Additional file}

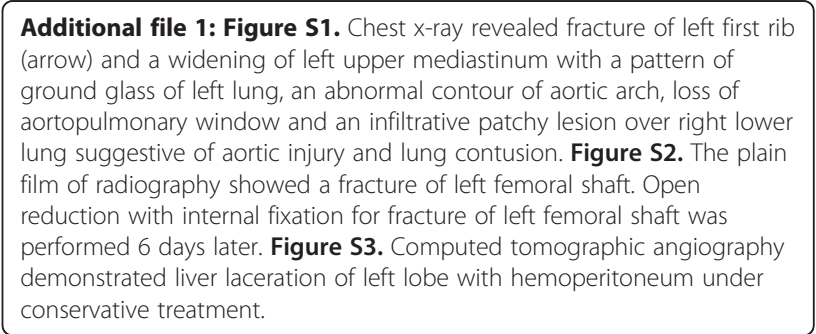

Competing interests

The authors declare that they have no competing interests.

\section{Authors' contributions}

LPS, HSY and LTC conducted primary survey, resuscitation and emergency care at emergency department. HSW prepared the radiological images. TCL performed the endovascular repair. LPS and HSY participated in the design of the case report and performed the search in the literature. LPS, HSY, LTC, HSW and TCL participated in the design and coordination of the report. All authors read and approved the final manuscript.

\section{Acknowledgements}

Thanks for efforts of emergency resuscitation team, radiological technicians, cardiovascular center, orthopedics, and trauma intensive care unit for clinical 


\section{Author details}

'Department of Emergency Medicine, Taichung Veterans General Hospital, Taichung, Taiwan. ${ }^{2}$ Division of Cardiovascular Surgery, Department of Surgery, Taichung Veterans General Hospital, Taichung, Taiwan. ${ }^{3}$ Department of Radiology, Taichung Veterans General Hospital, Taichung, Taiwan. ${ }^{4}$ School of Medicine, Chung Shan Medical University, Taichung, Taiwan. ${ }^{5}$ School of Medical Imaging \& Radiological Sciences, Chung Shan Medical University, Taichung, Taiwan. Institute of Medicine, Chung Shan Medical University, Taichung, Taiwan. ${ }^{7}$ Department of Nursing, College of Health, National Taichung University of Science and Technology, Taichung. ${ }^{8}$ Department of Veterinary Medicine, National Chung Hsing University, Taichung, Taiwan.

Received: 23 June 2012 Accepted: 25 February 2013

Published: 3 March 2013

\section{References}

1. Fattori R, Russo V, Lovato $L$, et al: Optimal management of traumatic aortic injury. Eur J Vasc Endovasc Surg 2009, 37(1):8-14.

2. Bizzarri F, Mattia C, Ricci M, et al: Traumatic aortic arch false aneurysm after blunt chest trauma in a motocross rider. J Cardiothorac Surg 2008, 3:23.

3. Berger FH, van Lienden KP, Smithuis R, et al: Acute aortic syndrome and blunt traumatic aortic injury: pictorial review of MDCT imaging. Eur J Radiol 2010, 74(1):24-39.

4. Kurimoto $Y, A$ sai $Y$, Nara $S$, et al: Fenestrated stent-graft facilitates emergency endovascular therapy for blunt aortic injury. J Trauma 2009, 66(4):974-978. discussion 978-9.

5. O'Connor JV, Byrne C, Scalea TM, Griffith BP, Neschis DG: Vascular injuries after blunt chest trauma: diagnosis and management. Scand I Trauma Resusc Emerg Med 2009, 17:42.

6. Oikonomou A, Prassopoulos P: CT imaging of blunt chest trauma. Insights Imaging 2011, 2(3):281-295.

7. Steenburg SD, Ravenel JG, Ikonomidis JS, Schönholz C, Reeves S: Acute traumatic aortic injury: imaging evaluation and management. Radiology 2008, 248(3):748-762.

8. Gammie JS, Shah AS, Hattler BG: Traumatic aortic rupture: diagnosis and management. Ann Thorac Surg 1998, 66(4):1295-1300.

9. Bruno VD, Batchelor TJ: Late aortic injury: a rare complication of a posterior rib fracture. Ann Thorac Surg 2009, 87(1):301-303.

10. Mazzaccaro D, Malacrida G, Occhiuto MT, Stegher S, Tealdi DG, Nano G: Endovascular treatment of iatrogenic axillary artery pseudoaneurysm under echographic control: a case report. J Cardiothorac Surg 2011, 6:78.

doi:10.1186/1749-8090-8-36

Cite this article as: Li et al.: Endovascular treatment for traumatic

thoracic aortic pseudoaneurysm: a case report. Journal of Cardiothoracic Surgery 2013 8:36.

\section{Submit your next manuscript to BioMed Central and take full advantage of:}

- Convenient online submission

- Thorough peer review

- No space constraints or color figure charges

- Immediate publication on acceptance

- Inclusion in PubMed, CAS, Scopus and Google Scholar

- Research which is freely available for redistribution 